\title{
Coexistence of gastrointestinal stromal tumor (GIST) and colorectal adenocarcinoma: A case report
} Papalambros Efstathios, Petrou Athanasios, Ioannis Papaconstantinou*, Papalambros Alexandros, Sigala Frangisca, Georgopoulos Sotirios, Felekouras Evangelos and Giannopoulos Athanasios

Address: First Department of Surgery, Athens Medical School, National and Kapodistrian University of Athens, LAIKO General Hospital, Greece

Email: Papalambros Efstathios - stpapalamp@med.uoa.gr; Petrou Athanasios - thpetrou@yahoo.gr;

Ioannis Papaconstantinou* - johnpapacon@ hotmail.com; Papalambros Alexandros - stpapalamp@hotmail.com;

Sigala Frangisca - fsigala@ukaachen.de; Georgopoulos Sotirios - sgeorg@med.uoa.gr; Felekouras Evangelos - felek@med.uoa.gr; Giannopoulos Athanasios - dimitrak@mohau.gr

* Corresponding author

Published: 2I August 2007

World Journal of Surgical Oncology 2007, 5:96 doi:10.1 186/1477-78/9-5-96

This article is available from: http://www.wjso.com/content/5/l/96

(c) 2007 Efstathios et al; licensee BioMed Central Ltd.

This is an Open Access article distributed under the terms of the Creative Commons Attribution License (http://creativecommons.org/licenses/by/2.0), which permits unrestricted use, distribution, and reproduction in any medium, provided the original work is properly cited.
Received: 13 December 2006

Accepted: 2I August 2007

\begin{abstract}
Background: Gastrointestinal stromal tumors (GIST) represent the most common mesenchymal tumors of the digestive tract. Over the last ten years the management of GISTs has dramatically altered but their coexistence with other gasrointesinal tumors of different histogenesis presents a special interest. The coexistence of GISTs with other primaries is usually discovered incidentally during $\mathrm{Gl}$ surgery for carcinomas.

Case presentation: We present here, a case of a 66-year-old patient with intestinal GIST and a synchronous colorectal adenocarcinoma discovered incidentally during surgical treatment of the recurrent GIST. Immunohistochemical examination revealed the concurrence of histologically proved GIST (strongly positive staining for c-kit, vimentin, SMA, and focal positive in S-100, while CD-34 was negative) and Dukes Stage C, (T3, N3, M0 according the TNM staging classification of colorectal cancer).

Conclusion: The coexistence of GIST with either synchronous or metachronous colorectal cancer represents a phenomenon with increasing number of relative reports in the literature the last 5 years. In any case of GIST the surgeon should be alert to recognize a possible coexistent tumor with different histological origin and to perform a thorough preoperative and intraoperative control. The correct diagnosis before and at the time of the surgical procedure is the cornerstone that secures the patients' best prognosis.
\end{abstract}

\section{Background}

Gastrointestinal stromal tumors (GISTs) are specific mesenchymal tumors that may occur anywhere along the gastrointestinal tract $[1,2]$. It is currently defined as gastrointestinal tract mesenchymal tumor containing spindle cells (less commonly epithelioid cells or both) and showing CD-117 (c-kit protein) and vimentin positivity $[1,3,4]$ 
GISTs are rare neoplasms and represent the $0.1-3 \%$ of all gastrointestinal cancers and the most common mesenchymal tumor of the digestive tract $(20 \%$ of small bowel malignancies \& approximately $5 \%$ of all tissue sarcomas) $[5,6]$.

Over the last years the management of GISTs has evolved rapidly. A lot of changes have been reported in histological diagnostic criteria, in understanding of GISTs' molecular biology and pathogenesis, in imaging strategy, in surgical and adjuvant treatment etc [7]. Although the outcomes of several published series helped in understanding their pathogenesis, little is known about their coincidence with other tumors of different histogenesis. There are some data regarding the co-occurrence, the association and the potential common origin (genetic pathways of tumorigenesis), between GIST and other tumors $[7,8]$. The limited number of these cases can not confirm the existence of a common factor in tumorigenesis of these histopathologically completely different tumors and further studies are needed to clarify the possible association [9].

The coexistence of GISTs with other primaries is usually discovered incidentally during GI surgery for carcinomas [10-12]. Here in, we describe the reverse of the common situation, as a cecal adenocarcinoma was incidentally discovered during surgery for recurrent intestinal GIST.

\section{Case presentation}

A 66-year-old man was admitted to our clinic two years ago complaining abdominal discomfort associated with distension, pain, and symptoms related to small intestine bowel obstruction (vomiting and obstipation). On physical examination a palpable mass in the lower right abdomen was found. CT scan of the abdomen and pelvis demonstrated a large $(9 \times 6.5 \times 7 \mathrm{~cm})$ low-density, well circumscribed mass in the right lower abdomen, without evidence of tumor infiltration of adjacent structures and without free fluid. No metastatic nodules were found in the liver and the lung.

Laparotomy revealed a pedunculated, ulcerative and friable large mass (a small bowel mass greater than $10 \mathrm{~cm}$ ) with the features of gastroimtestinal stromal tumor: the surrounding organs (sigmoid colon, rectum, ureters and bladder) were pushed but not involved by the tumor. Furthermore, remarkable intraabdominal metastatic spread consisted of multiple small nodular lesions - less than 2 $\mathrm{cm}$ in size - all over the peritoneal surface and between bowel loops, was encountered. No evidence of liver metastasis or lymphadenopathy was found. The patient underwent an en-block resection of the tumor along with all visible disease in order to avoid capsule rupture and intraabdominal spillage, as is recommended [7]. A small bowel resection with an end to end primary anastomosis was performed. Numerous peritoneal nodal metastases were excised and sent for histological analysis.

Histopathological examination of the resected specimens revealed a stromal cell neoplasm with necrotic and hemorrhagic areas and a high index of mitotic count: 8-10 mitoses per high-power fields (HPF). Immunohistochemical analysis revealed C-kit (strongly positive), SMA(strongly positive), focal S-100(+) and CD34(-). The result of histological examination confirmed also the existence of intraabdominal metastatic spread.

Following the histopathological confirmation, immediate treatment with imatinib was initiated. The imatinib was introduced in dose of $400 \mathrm{mg} /$ day without interruption (in order to minimize the risk of relapse associated with the drug interruption) [10]. Postoperatively, patient was followed up with CT scan. According to the clinical, surgical and histopathological features, our patient was included in the high risk group for recurrence. The patient underwent a CT scan of the abdomen and the pelvis in regular 4-6 months intervals $[13,14]$.

The CT scan performed 2 years after surgical excision and treatment commencement, revealed metastatic liver disease. Dose escalation ( $400 \mathrm{mg}$ of imatinib mesylate twice a day) was decided and initiated. Six months later, liver lesion was presented with a characteristic size increase (figure 1a). Furthermore, a small soft tissue mass $(3,3 \times$ $2,8 \times 3 \mathrm{~cm}$ ) in the right lower abdomen was revealed in the abdominal CT scan. The mass was localized at the anatomic area of the previous excision and was considered either as another metastatic lesion or as a possible local recurrence (figure $1 \mathrm{~b}$ ).

Laparotomy confirmed the presence of liver metastasis, localized between the Segment V \& Segment VI as well as intra-abdominal metastatic spread (multiple small nodular lesions - less than $1 \mathrm{~cm}$ in size - all over the peritoneal surface and between bowel loops). An intestinal mass was also found $60 \mathrm{~cm}$ proximal to the ileocecal valve. Surprisingly, during the thorough exploration of the peritoneal cavity, another mass with completely different macroscopic features was discovered. It was a palpable cecal mass, without extracanalicular growth or infiltration into other organs, associated with local lymph-node enlargement.

Intra-abdominal ultrasound (IOUS) was performed in order to assist in liver resection planning (mainly to enable detection of additional tumors, missed in preoperative CT scan imaging and to evaluate the relationship between metastatic lesions and major vascular structures). 


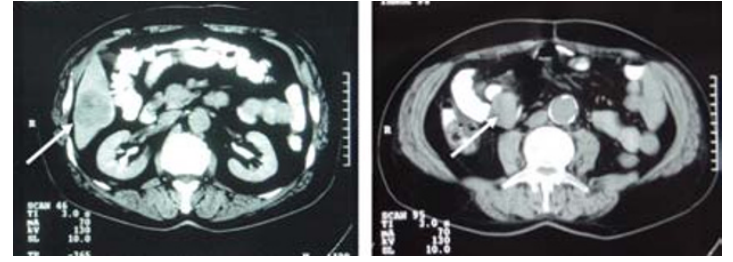

\section{Figure I}

A: CT scan of the abdomen revealing, A: a $5 \times 5.2 \mathrm{~cm}$ liver mass (white arrow) located between segments $\mathrm{V}$ and $\mathrm{VI}$ and B: a $4 \times 3.8 \mathrm{~cm}$ soft tissue mass (white arrow) in the right abdomen between bowel loops.

RFA (Radio Frequency Ablation)-assisted liver resection [15] of segments V, VI was performed and a segmental small-bowel resection along with excision of all gross visible peritoneal nodular lesions followed. Finally, a right hemicolectomy was decided in order to treat the "unexpected" cecal lesion.

At this point is important to underline that surgery remains the mainstay therapy for both (GIST and colorectal cancer) although the operative strategies and extent of resection are fairly different. [12] Given the rarity of lymph-node involvement, routine lymphadenectomy is not currently recommended in GIST cases. [13,16] At the present case because of local lymph-node enlargement a curative resection was performed (included the resection of the lymphatic station), aiming to obtain microscopic disease-free radial and distal margins.

Gross examination of the $29 \mathrm{~cm}$ specimen disclosed a $7 \times$ $4 \mathrm{~cm}$ tumor originating from the cecum and two polyps located about $7 \mathrm{~cm}$ from the cecum. The liver specimen $(8.5 \times 6.5 \times 3.7 \mathrm{~cm}$, segments $\mathrm{V}, \mathrm{VI})$ weighted $90 \mathrm{gr}$ and contained the $5 \mathrm{~cm}$ metastatic lesion.

Histopathological examination of the resected specimen (figure 2) revealed a recurrent intestinal GIST (figure 2A,B) with malignant biological behavior and a moderately differentiated stage Dukes C (T3, N3, M0 according the TNM staging classification of colorectal cancer) cecal adenocarcinoma (figure $2 \mathrm{C}$ ).

The specimen had the following characteristics: a) metastatic liver tumor with mesenhymal origin characterized by necrotic and bleeding areas (figure 2D) and a mitotic count of $<5 / 50 \mathrm{HPF}$. Immunohistochemical staining revealed a strongly $(+)$ reaction for c-kit, slight $(+)$ for $\mathrm{S}$ 100 , and no specific staining for CD34 and desmin. The surgical margins of the resected hepatic specimen were free from invasion, b) moderately differentiated adenocarcinoma with a slight extracellular, mucus production.
The tumor invaded the muscularis propria and the pericolonic adipose tissue. The neoplastic tissue extended and infiltrated the small bowel wall but the proximal and distant surgical margins were free.

Four of the examined lymph nodes presented metastatic invasion from GIST and 12 from colorectal adenocarcinoma. The above mentioned morphologic and immunochistochemical findings are diagnostic for coexistence of GIST and colorectal adenocarcinoma

\section{Discussion}

Gastrointestinal stromal tumors are uncommon and their pathogenesis, diagnosis, nomenclature, and prognosis have long been a subject of considerable controversy. The stromal tumors designated as GISTs are identified by a series of histological, molecular, genetic and in particular, immunophenotypic features that set them apart from common leiomyomas, leiomyosarcomas of the GI-tract. Recent studies suggest that GISTs represent a subgroup of gastrointestinal mesenchymal tumors arising from a common precursor cell, the interstitial cell of Cajal, or a primitive stem cell from which both Cajal cells and smooth muscle cells arise [3]. Gastrointestinal stromal tumors are currently defined as c-kit (CD117)-positive spindle cell (or, less commonly, epithelioid cell or both) gastrointestinal tract mesenchymal tumors $[1,3]$.

The most important markers for defining GISTs are CD 117 (c-kit protein) and CD 34 (hematopoietic cell progenitor antigen). The majority of GISTs are usually positive for CD117 (near 95\% of cases), CD34 (positive in $70-80 \%$ of cases), smooth muscle actin (positive in $40 \%$ of cases), PS 100 (positive near 5\% of cases), and desmin (positive in approximately 2\% of cases) [1-3].

Although the demonstration of c-kit (CD117) immunoreactivity represents the gold standard for diagnosis of GIST (it's also considered as an eligibility criterion for Imatinib Masylate therapy) [2,3] approximately 5\% of histologocally suspected GIST are CD117 negative $[1,17,18]$.

Gastrointestinal stromal tumors may occur anywhere along the digestive tract. They may be found anywhere between the esophagus and the anus. Additional locations have been found to include omentum, mesentery and retroperitoneum $[18,19,21]$. Most GISTs arise from the stomach (50-62\%), from the small intestine (20-30\%), the colon $(11 \%)$, the rectum $(7 \%)$ while the esophagus is rarely involved $(0,6-1 \%)[19,20,22]$.

It is well known that GISTs have the potential to metastasize (at first diagnosis many patients present with metastatic spread (11-47\%) [22] either via blood stream or via peritoneal seeding and they give rise to liver or omental 

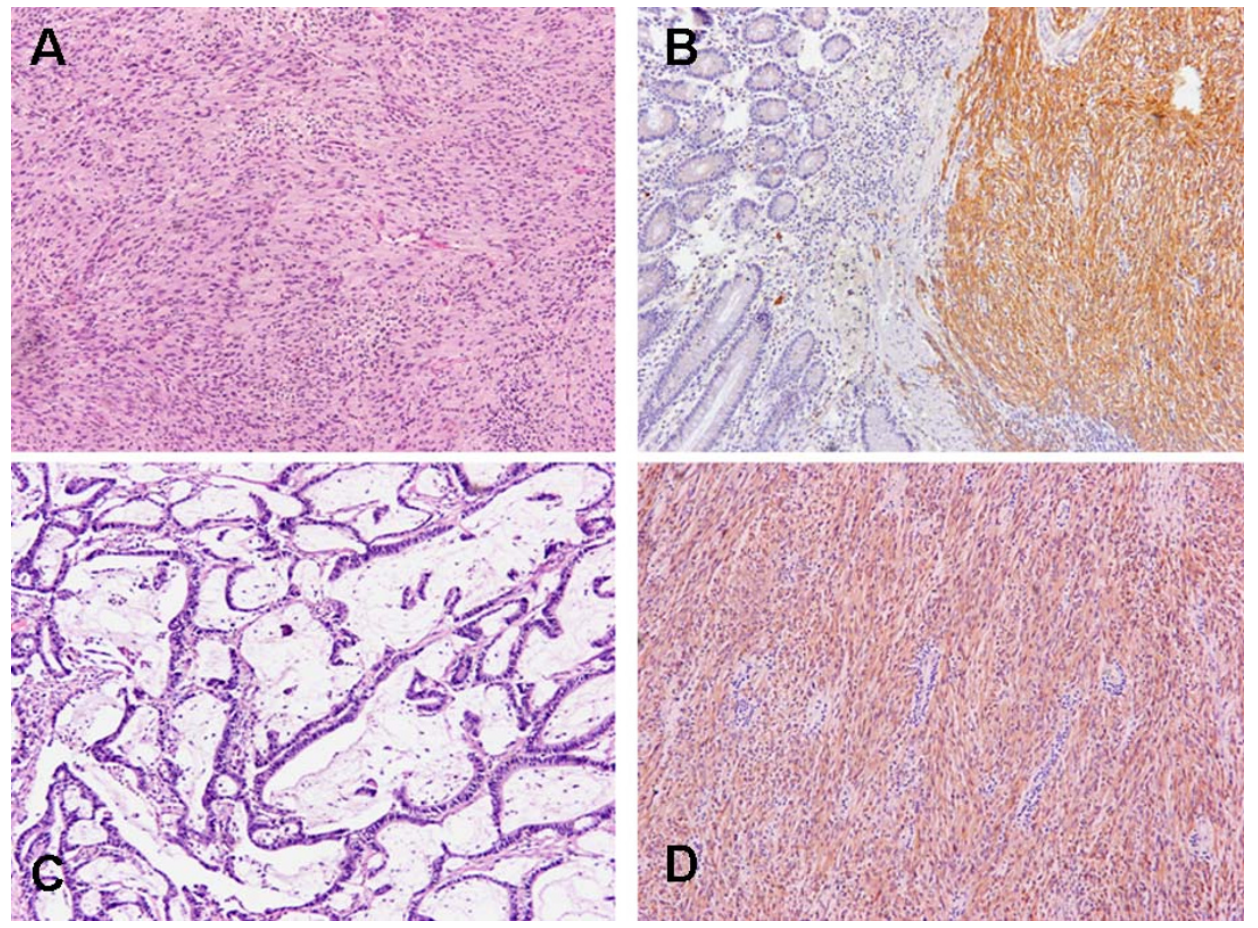

\section{Figure 2}

A: Small intestine GIST in H-E stain $(\times 20)$; B: C-kit immunoexpression $(\times 40)$; C: Adenocarcinoma of cecum in $\mathrm{H}-\mathrm{E}$ stain $(\times 20)$; D: C-kit immunoreactivity in metastatic GIST of liver $(\times 20)$.

metastases. Lung, bones and lymph node metastases are rare $[1,2]$. GISTs' malignant potential is considered to depend on tumor size, frequency of mitoses, presence of necrosis, and the possible invasion to adjacent organs [2124 ] but there is also a relevance to the anatomic site of origin [3].

In the described case, a 66-year-old male was operated primarily for a small bowel tumor in surgical emergency setting. The tumor was treated as malignant because, according to the guidelines, in a surgical emergency or in the absence of a preoperative diagnosis, even in the presence of a single mass without evidence of contiguous organ involvement or metastatic disease, the surgeon is responsible to recognize and to treat these lesions as malignant [25]. Histopathologic findings confirmed the presence of intestinal GIST with a highly malignant behavior. Reported series in pre-imatinib era indicated that the complete surgical excision, although technically feasible, is not curative and the use of imatinib in unresectable and/or metastatic disease is recommended [13]. Indeed, the patient was further treated with imatinib mesylate and underwent the indicated by ESMO follow up.
Two years after treatment initiation, during follow-up CT scan, a liver mass was found. The liver mass failed to respond to the appropriate imatinib dose escalation (400 mg twice day). Additionally, at the subsequent follow up, an intestinal mass at the site of previous surgical excision was discovered, which was initially confused with other similar metastatic lesions demonstrated between small bowel loops.

Surgery followed and the subsequent histopathological examination confirmed the presence of the GIST liver metastasis and a moderately differentiated cecal adenocarcinoma. a fact that renders the potential promising therapeutic impact of imatinib mesylate in the prevention of colorectal cancer controversial (this was shown by the inhibition of the in vitro growth of the colorectal carcinoma cell lines) [26].

There is a continuously increasing knowledge about synchronous presentation of GIST and other gastrointestinal tumors. The major types of GIST-associated malignancies reported in literature are: gastrointestinal carcinomas (gastric and colon cancer), lymphoma/leukemia, gynecological carcinomas, and carcinomas of prostate, breast, pancreas, lung, liver, kidney as well as carcinoid of pan- 
creas and stomach [10-12,27-30]. Although uncommon, the fact that patients who have a history of soft tissue sarcomas (STS) are in an increased risk for the development of GIST, presents a special interest [30,31].

Even if the synchronous occurrence of GIST and colorectal adenocarcinomas is not extremely rare little is yet known their potential common origin and carcinogenetic pathways. The limited number of reported cases cannot rule out a possible incidental occurrence though [32,33]. The majority of the coexistent GISTs are discovered incidentally during work-up or during therapeutic procedures for GI malignancies. What is unique in the present case is that synchronous cecal adenocarcinoma was incidentally discovered during laparotomy for recurrent GIST disease.

What should be delineated at this point is the undeniable possible coexistence of a synchronous tumor with a primary or recurrent GIST. This fact underlines the significance of a detailed preoperative imaging study which should include contrast enhanced CT scans of the abdomen and pelvis. Other modalities used in the evaluation of GISTs include MRI and Fluorodeoxyglcose positron emission tomography (PET) but CT is currently the imaging modality of choice. Above all, we should emphasize the importance of a thorough intrabdominal exploration by an experienced surgeon in order not to overlook a possible mass that could hide a synchronous cancer.

\section{Conclusion}

The coexistence of GIST with either synchronous or metachronous colorectal cancer represents a phenomenon with increasing number of relative reports in the literature the last 5 years.

In any case of GIST (with or without preoperative histopathological confirmation) the surgeon should be alert to recognize a possible coexistent tumor with different histological origin and to perform a thorough preoperative and intraoperative control. The correct diagnosis before and at the time of the surgical procedure is the cornerstone that secures the patients' best prognosis.

\section{Competing interests}

The author(s) declare that they have no competing interests.

\section{Authors' contributions}

PE: author and supervisor of the manuscript.

PA: editing.

PI: editing.

PA: collection of the literature.
SF: collection of the literature.

GS: revision of the manuscript.

FE: revision of the manuscript.

GA: supervisor of the manuscript and final revision.

\section{Acknowledgements}

Written informed consent was obtained from the patient for publication of this case report.

\section{References}

I. Miettinen M, Lasota J: Gastrointestinal stromal tumors - definition, clinical, histological, immunohistochemical, and molecular genetic features and differential diagnosis. Virchows Arch 200I, 438: I- I 2 .

2. Miettinen M, Sarlomo-Rikala M, Sobin LH, Lasota J: Gastrointestinal stromal tumors and leiomyosarcomas in the colon: a clinicopathologic, immunohistochemical, and molecular genetic study of 44 cases. Am J Surg Pathol 2000, 24: 1339-1352.

3. Fletcher CD, Berman JJ, Corless C, Gorstein F, Lasota J, Longley BJ, Miettinen M, O'Leary TJ, Remotti H, Rubin BP, Shmookler B, Sobin $\mathrm{LH}$, Weiss SW: Diagnosis of gastrointestinal stromal tumors: a consensus approach. Int / Surg Pathol 2002, 10:81-89.

4. Pidhorecky I, Cheney RT, Kraybill WG, Gibbs JF: Gastrointestinal stromal tumors: current diagnosis, biologic behavior, and management. Ann Surg Oncol 2000, 7:705-7I2.

5. Chou FF, Eng HL, Sheen-Chen SM: Smooth muscle tumors of the gastrointestinal tract: analysis of prognostic factors. Surgery 1996, I I 9: I7|- I77.

6. Lewis JJ, Brennan MF: Soft tissue sarcomas. Curr Probl Surg 1996, 33:817-872.

7. Maiorana A, Fante R, Maria Casinaro A, Adriano Fano R: Synchronous occurrence of epithelial stromal tumors in the stomach: a report of 6 cases. Arch Pathol Lab Med 2000, 124:682-686.

8. Sugimura T, Fujimura S, Baba T: Tumor production in the glandular stomach and alimentary tract of the rat by $\mathrm{N}$-methylN'-nitro-N-nitrosoguanidine. Cancer Res 1970, 30:455-465.

9. Melis M, Choi EA, Anders R, Christiansen P, Fichera A: Synchronous colorectal adenocarcinoma and gastrointestinal stromal tumor (GIST). Int I Colorectal Dis 2006, 22: 109-I I4.

10. Agaimy A, Wunsch PH, Sobin LH, Lasota J, Miettinen CM: Occurrence of other malignancies in patients with gastrointestinal stromal tumors. Semin Diagn Pathol 2006, 23(2): I 20-129.

II. Kover E, Faluhelyi Z, Bogner B, Kalmar K, Horvath G, Tornoczky T: [Dual tumours in the GI tract: synchronous and metachronous stromal (GIST) and epithelial/neuroendocrine neoplasms]. Magy Onkol 2004, 48:315-32I.

12. Usui M, Matsuda S, Suzuki H, Hirata K, Ogura Y, Shiraishi T: Somatostatinoma of the papilla of Vater with multiple gastrointestinal stromal tumors in a patient with von Recklinghausen's disease. I Gastroenterol 2002, 37:947-953.

13. Blay JY, Bonvalot S, Casali P, Choi H, Debiec-Richter M, Dei Tos AP, Emile JF, Gronchi A, Hogendoorn PC, Joensuu H, Le Cesne A, McClure J, Maurel J, Nupponen N, Ray-Coquard I, Reichardt P, Sciot R, Stroobants S, van Glabbeke M, van Oosterom A, Demetri GD: Consensus meeting for the management of gastrointestinal stromal tumors. Report of the GIST Consensus Conference of 20-21 March 2004, under the auspices of ESMO. Ann Oncol 2005, 16:566-578.

14. Demetri GD, Benjamin R, Blanke CD: Optimal management of patients with gastrointestinal stromal tumors: expansion and update of NCCN Clinical Practice Guidelines. J Comprehensive Cancer Network 2004, 2(suppl I): I-26.

15. Felekouras E, Prassas E, Kontos M, Papaconstantinou I, Pikoulis E, Giannopoulos A, Tsigris C, Tzivras M, Bakogannis C, Safioleas M, Papalambros E: Liver tissue dissection: ultrasonic or RFA energy? World J Surg 2006, 30:2210-2216.

16. De Matteo RP, Lewis JJ, Leung D, Mudan SS, Woodruff JM, Brennan MF: Tow hundred gastrointestinal stromal tumors: rec- 
curence patterns and prognostic factors for survival. Ann Surg 2000, $231: 5 I-58$.

17. Goettsch WG, Bos SD, Breekveldt-Postma N, Casparie M, Herings RM, Hogendoorn PC: Incidence of gastrointestinal stromal tumors is underestimated: Results of a nation-wide study. Eur J Cancer 2005, 42:2868-2872.

18. Corless CL, Schroeder A, Griffith D, Town A, McGreevey L, Harrell P, Shiraga S, Bainbridge T, Morich J, Heinrich MC: PDGFRA Mutations in Gastrointestinal Stromal Tumors: Frequency, Spectrum and in Vitro Sencitivity to Imatinib. J Clin Oncol 2005, 23:5357-5364.

19. Miettinen M, El-Rifai W, L HLS, Lasota J: Evaluation of malignancy and prognosis of gastrointestinal stromal tumors: a review. Hum Pathol 2002, 33:478-483.

20. Tran T, Davilla JA, El-Serag HB: The epidimiology of the malignant gastrointestinal stromal tumors: an analysis of 1458 cases from I 992 to 2000. Am J Gastroenterol 2005, I 00: | 62- I68.

21. Amin MB, Ma CK, Linden MD, Kubus JJ, Zarbo RJ: Prognostic value of proliferating cell nuclear antigen index in gastric stromal tumors. Correlation with mitotic count and clinical outcome. Am J Clin Pathol 1993, 100:428-432.

22. Rossi CR, Mocellin S, Mencarelli R, Foletto M, Pilati P, Nitti D, Lise M: Gastrointestinal stromal tumors: from a surgical to a molecular approach. Int J Cancer 2003, I07:171-I76.

23. Lerma E, Oliva E, Tugues D, Prat J: Stromal tumours of the gastrointestinal tract: a clinicopathological and ploidy analysis of 33 cases. Virchows Arch 1994, 424:19-24.

24. Shiu MH, Farr GH, Papachristou DN, Hajdu SI: Myosarcomas of the stomach: natural history, prognostic factors and management. Cancer 1982, 49:177-I87.

25. Rossi CR, Mocellin S, Mencarelli R, Foletto M, Pilati P, Nitti D, Lise M Gastrointestinal stromal tumors: from a surgical to a molecular approach. Int J Cancer 2003, 107:171-176.

26. Attoub S, Rivat C, Rodrigues S, Van Bocxlaer S, Bedin M, Bruyneel E Louvet C, Kornprobst M, Andre T, Mareel M, Mester J, Gespach C: The c-kit tyrosine kinase inhibitor STI57I for colorectal cancer therapy. Cancer Res 2002, 62:4879-4883.

27. Ruka W, Rutkowski P, Nowecki IZ, Nasierowska-Guttmejer A, Debiec-Rychter $M$ : Other malignant neoplasms in patients with Gastrointestinal Stromal Tumors (GIST). Med Sci Monit 2004, I0:LEI3-I4.

28. Au WY, Ho KM, Shek TW: Papillary renal cell carcinoma and gastrointestinal stromal tumor: a unique association. Ann Oncol 2004, I 5:843-844.

29. Jaworski R, Jastrzebski T, Swierblewski M, Drucis K, Kobierska-Gulida $\mathrm{G}$ : Coexistence of hepatocellular carcinoma and gastrointestinal stromal tumor: a case report. World J Gastroenterol 2006, 12:665-667.

30. Agaimy A, Wuensch PH: Gastrointestinal Stromal Tumors in patients with Other-Type Cancer: A Mere Incidence or an Etiological Association? A Study of 97 GIST cases. Z Gastroenterol 2005, 43: 1025-1030.

31. Grobmyer SR, Luther N, Antonescu RC, Singer S, Brennan FM: Multiple primary soft tissue sarcomas. Cancer 2004, | 0 I:2633-2635.

32. Maiorana A, Fante R, Maria Casinaro A, Adriano Fano R: Synchronous occurrence of epithelial stromal tumors in the stomach: a report of 6 cases. Arch Pathol Lab Med 2000, I 24:682-686.

33. Sugimura T, Fujimura S, Baba T: Tumor production in the glandular stomach and alimentary tract of the rat by $\mathrm{N}$-methylN'-nitro-N-nitrosoguanidine. Cancer Res 1970, 30:455-465.
Publish with Biomed Central and every scientist can read your work free of charge

"BioMed Central will be the most significant development for disseminating the results of biomedical research in our lifetime. "

Sir Paul Nurse, Cancer Research UK

Your research papers will be:

- available free of charge to the entire biomedical community

- peer reviewed and published immediately upon acceptance

- cited in PubMed and archived on PubMed Central

- yours - you keep the copyright
BioMedcentral 